\title{
The molecular basis of selective permeability of connexins is complex and includes both size and charge
}

B.J. Nicholson ${ }^{1}$, P.A. Weber ${ }^{1}$, F. $\mathrm{CaO}^{1}$, H.-C. Chang'2, P. Lampe 3 and G. Goldberg ${ }^{1}$

\author{
Departments of ${ }^{1}$ Biological Sciences and ${ }^{2}$ Chemical Engineering, \\ State University of New York at Buffalo, Buffalo, NY, USA \\ ${ }^{3}$ Fred Hutchinson Cancer Research Center, Seattle, WA, USA
}

\section{Correspondence}

B.J. Nicholson

619 Cooke Hall

SUNY at Buffalo

Buffalo, NY 14260-1300

USA

Fax: + 1-716-645-2871

E-mail: bjn@ acsu.buffalo.edu

Presented at the Meeting

"Gap Junctions in the Nervous and

Cardiovascular Systems: Clinical

Implications", Rio de Janeiro, RJ,

Brazil, June 6-11, 1998.

Research supported by NIH grants No. 48773 from NIGMS and

No. 48049 from NCl, as well as a

Whittaker grant No. PNU 1608 to

B.J. Nicholson, and a Wendy Will

Case Cancer Fund grant to $\mathrm{G}$.

Goldberg.

The current address of $\mathrm{F}$. Cao is Emory University School of Medicine, Atlanta, GA, USA, and the current address of $\mathrm{G}$. Goldberg is

Experimental Pathology and Chemotherapy, National Cancer Center Research Institute, Tokyo, Japan.

Received July 7, 1999 Accepted July 28, 1999

\section{Abstract}

Although gap junction channels are still widely viewed as large, nonspecific pores connecting cells, the diversity in the connexin family has led more attention to be focused on their permeability characteristics. We summarize here the current status of these investigations, both published and on-going, that reveal both charge and size selectivity between gap junction channels composed of different connexins. In particular, this review will focus on quantitative approaches that monitor the expression level of the connexins, so that it is clear that differences that are seen can be attributed to channel properties. The degree of selectivity that is observed is modest compared to other channels, but is likely to be significant for biological molecules that are labile within the cell. Of particular relevance to the in vivo function of gap junctions, recent studies are summarized that demonstrate that the connexin phenotype can control the nature of the endogenous traffic between cells, with consequent effects on biological effects of gap junctions such as tumor suppression.

\section{Introduction}

Notwithstanding speculation regarding possible roles for hemichannels (1-3), or the association of cellular components with the cytoplasmic domains of connexins (4-8), the only demonstrable physiological function that has been associated with gap junctions to date has been their unique ability to mediate the direct exchange of small metabolites between cells. This is still characterized in textbook descriptions in terms of non-specific permeability to molecules of molecular weight (MW) under 1000 (slightly higher in the case of invertebrates). However, the di-
Key words

- Intercellular channels

- Permeability

- Gap junctions
- Channel selectivity versity within the connexin family has begged the question of how the connexin composition of these channels can affect the character of the information that is exchanged between cells.

Although several early studies had indicated that the permeability of gap junctions could vary in different tissues, there was no characterization of the connexin phenotype in these cases. With the generation of several cell lines expressing different connexins on a background of minimal endogenous coupling (e.g., HeLa cells (9), N2A cells (10)), comparisons of permeability characteristics using both electrical measurements and inter- 
cellular diffusion of fluorescent dyes were initiated. The emerging picture, which we summarize here, is complex. Connexin composition can bias the selection of permeants based on their charge, but there are also growing indications that different connexins can impose distinct size limits on permeant species. Finally, we are beginning to approach the Holy Grail of this quest - the identification of connexin-induced selectivity between metabolites of biological significance. The early indications from these studies is that some of the selectivity that is displayed is not easily explained in terms of size and charge alone, but may involve more specific interactions of the permeants with the channel wall.

\section{Charge selectivity of connexins}

As in most other channels, the first efforts to investigate the selectivity of gap junction channels for charge were to examine the effects of substituting larger, and hence slower diffusing, anions or cations on the conductance of the channel. Unfortunately, the size of the gap junction channels is such that there were virtually no ions large enough that they would be excluded from the pore. Hence, only graded reductions in conductance could be recorded, and these were only significant with large changes in ion size that also usually meant changes in shape and charge density (e.g., compare $\mathrm{Cl}^{-}$ to glutamate; $\mathrm{Na}^{+}$to tetra-butyl ammonia). Nonetheless, an extensive series of comparisons on whole channels (11-13) and hemichannels (14) revealed a range of modest ion selectivities from an 8-fold preference for cations (Cx40 (12) and 43 (13)) to a very slight anion preference ( $\sim 6 \%$ in $\mathrm{Cx} 32(15))$. This represents modest ion selectivity with respect to most ion channels, but may prove quite significant when considering permeants that have limited half-lives in the recipient cell. It also is likely that the degree of selectivity may become greater with larger permeants comparable to endogenous metabolite traffic between cells.

Some efforts have been made to examine larger permeants in transfected cells with visibly detectable dyes. Comparison of a series of connexins expressed in HeLa cells found significant differences in the relative permeabilities of probes such as anionic Lucifer yellow, and cationic propidium iodide, ethidium bromide and neurobiotin (9). The results suggested that charge might play a role, although clearly these probes also varied with respect to other properties. However, the real limitation of this approach was the lack of quantitation that was possible, as there was no independent assessment of expression levels of the various transfected connexins. We have tried to address this problem in the same cells by recording the electrical conductance between neighbors in a monolayer. As all of the cells in the monolayer are coupled, this does not provide a direct measure of the junctional conductance between cell pairs, but rather reflects the conductance of the monolayer. Nonetheless, this does provide an independent measure of the expression of functional channels. Comparing cultures of HeLa cells expressing three different connexins at similar levels, we showed that the same cultures of Cx32, 26 and 45 transfected cells showed decreasing permeabilities to anionic Lucifer yellow, but increasing permeabilities to the cationic dye DAPI (Table 1, modified from Ref. 16). This could be done by comparing the percent of first order cells surrounding the injected cell that were filled and normalizing this result to the conductance level of the monolayer taken in the same dish. Alternatively, the cumulative plot of fraction of cell pairs with conductances above a given level can be compared to the fraction of cells that show dye coupling to provide an estimate of the conductance threshold that must be exceeded in order to see transfer of each dye. In this case, the larger the number, the less permeable the channel is to that dye. 
Although the two dyes studied here also differed significantly in size, the inverse pattern of permeabilities observed could not be accounted for by size alone, and supported the contention that charge plays a critical role in the selectivity characteristics of connexins to larger permeants.

Despite the improvement in the normalization of dye transfer to expression levels of the channels achieved in this work, the potential remains limited, as the monolayer conductance is not directly proportional to the conductance between an isolated pair of cells. Also, these measurements cannot be made on the same cells into which the dye is injected. An attempt to improve the situation was made using a Xenopus oocyte pair injected with the relevant cRNA. In this system, the conductance (before and after dye injection) and dye transfer can be measured on the same cell pair. This allowed us to obtain accurate estimates of the permeability of these three connexins to Lucifer yellow, confirming the order established in the HeLa monolayers. With this more quantitative approach, $\mathrm{C} \times 32$ was determined to be $\sim 6$-fold more permeable to Lucifer yellow than $\mathrm{Cx} 26$ (16). Unfortunately, the binding capacity of the oocyte yolk for positive charges prevents the use of any cationic dyes.

\section{Size exclusion limits of different connexins}

Characterization of the electrophysiological properties of connexins revealed a remarkable range of single channel conductances $\left(\gamma_{\mathrm{j}}\right)$ from $30 \mathrm{pS}(\mathrm{Cx} 56$ (17) and $\mathrm{Cx} 45$ (18)) to $\sim 300 \mathrm{pS}(\mathrm{Cx} 37(10,19))$. Although suggestive of a wide range of pore sizes, in other channel classes the single channel conductances have not correlated well with pore size. In gap junctions this also seems to be the case, as an extensive comparison by Veenstra and colleagues (11) has shown that smaller conductances are not necessarily associated with greater selectivity, as exempli- fied by $\mathrm{Cx} 32$ that has a relatively small single channel conductance of $55 \mathrm{pS}$ (20) but shows almost no ionic preference (15). Initial estimates of the pore size of gap junctions used fluorescent probes that varied in both size and other properties such as charge and shape. Loewenstein $(21,22)$ developed a graded series of probes that had more uniform properties and helped to establish the initial estimates of size cut-off at $1000 \mathrm{Da}$ for vertebrate gap junctions and 2000 Da for invertebrate gap junctions. In none of these earlier studies, of course, was the composition of the channels known, or was it even recognized that invertebrates and vertebrates do not utilize related protein families to form these channels.

Once cell lines expressing defined populations of connexins were developed, most comparative studies still used probes that differed in multiple properties, so that the influence of size could not readily be isolated. Nonetheless, studies on some osteoblast cell lines expressing either $\mathrm{Cx} 43$ or $\mathrm{Cx} 45$ showed that the latter did not pass the dye Lucifer yellow, even when well coupled (23). Furthermore, co-expression of $\mathrm{Cx} 45$ with $\mathrm{Cx} 43$ served to reduce the capacity for

Table 1 - Transfer of Lucifer yellow and DAPI dyes within a HeLa cell monolayer transfected with different connexins.

${ }^{1}$ The percentage of first order cells receiving dye from an injected cell was measured ( $n$ ranging from 14 to 49 ), and normalized to the conductance levels in the same dish of cells. Conductance of the cell monolayer was estimated from an average of dual-cell voltage clamp recordings of neighboring cells.

${ }^{2}$ Cumulative plots of the numbers of cell pairs within the monolayer showing particular conductance levels and those showing detectable passage of dye were compared to establish the coupling threshold for each connexin that is required to detect transfer of a particular dye.

3 Lucifer yellow is an anionic dye (-2 charge) of MW 443.

${ }^{4}$ DAPI (4',6-diamidino-2-phenylindole) is a cationic dye (+2 charge) of MW 279.

\begin{tabular}{|c|c|c|c|c|}
\hline \multirow[t]{2}{*}{$\begin{array}{l}\text { HeLa transfectant } \\
\text { Cx }\end{array}$} & \multicolumn{2}{|c|}{$\begin{array}{l}\text { \%Primary neighbors coupled } \\
\text { (corrected for conductance) }^{1}\end{array}$} & \multicolumn{2}{|c|}{$\begin{array}{l}\text { Minimum conductance for } \\
\text { detection of dye transfer (nS) }\end{array}$} \\
\hline & Lucifer yellow 3 & $\mathrm{DAPI}^{4}$ & Lucifer yellow 3 & DAPI ${ }^{4}$ \\
\hline 32 & 72 & 26 & 10 & 30 \\
\hline 26 & 46 & 66 & 25 & 10 \\
\hline 45 & 23 & 84 & 30 & 8 \\
\hline
\end{tabular}


dye coupling while increasing electrical connectivity (24). The first diversion from this pattern was a study on hemichannels reconstituted into liposomes from solubilized gap junctions isolated from rat or mouse liver (25). These junctions contained a predominance of $\mathrm{Cx} 32$ or approximately equimolar amounts of $\mathrm{Cx} 32$ and $\mathrm{Cx} 26$, respectively. Harris and colleagues (25) used a series of pyridine derivatives of poly-maltose whose leakage from the liposomes could be detected fluorescently. These probes are neutral, and as maltose monomers are added to the chain, the chirality of the $\alpha$ 1-4 linkage produces a spiral structure, the outside diameter of which increases predictably up to the hexameric form. These molecules are subject to glycosidic cleavage in cells, but they are stable and useful in the reconstituted system employed here. The results were quite dramatic, in that the dimeric and monomeric forms leaked readily from liposomes reconstituted from either connexin population, but the trimeric form only leaked from the liposomes containing reconstituted channels from the rat liver (containing a predominance of Cx32). Tetrameric and higher forms were retained by all liposomes. This strongly suggests that, despite the higher single channel conductance of Cx26 ( 135 pS) compared to $\mathrm{Cx} 32(\sim 55 \mathrm{pS})(15,20)$, channels containing more $\mathrm{Cx} 26$ show a reduced cut-off limit in terms of the size of the permeant species.

As an alternative to changing the permeant species, Verseilis and colleagues applied a novel approach to the comparison of permeabilities of wild type Cx32 and several mutants associated with X-linked CharcotMarie-Tooth (CMTX) disease (26). By adding high percentages of various polyethylene glycol derivatives ranging in size from 200 to 900 , as well as glycerol and mannitol, it was found that the movement of ions between the cells, measured by junctional conductance, could be reduced, but only in the cases where the PEG variant was small enough to enter the pore. The theory is that the neutral PEG, if it enters the pore, will provide significant interference with the flux of charged ions, thus reducing conductance. This would not occur in the cases of PEGs that are excluded from the pore. This strategy provided compelling support for the contention that some of the CMTX-associated mutants, while forming functional channels, showed significantly reduced pore size. This is a powerful technique, but again is limited to cases where the intracellular milieu can be effectively exchanged for a solution of defined composition.

The recent availability of a new series of fluorescent probes, termed Alexa, from Molecular Probes has made it feasible to return to the more classical, and broadly applicable approaches to comparing junctional permeability of different connexins. These probes are relatives of fluorescein that carry a net charge of -1 . A graded size series of these probes has been produced with fluorophores composed of 2 (MW 349), 3 (MW 570) and 5 (MW 759) conjugated aromatic rings. The charge density of the probes is comparable, as the smallest carries one negative charge, while the larger two have one positive and two negative charges. This avoids some of the influence of charge distribution over the surface of the probe that was shown to influence permeability in di-chloro- and 6-carboxy-derivatives of fluorescein (11). In order to improve quantitative comparisons of the flux of these dyes through gap junction channels composed of different connexins, we utilized these probes in paired Xenopus oocytes that had been injected with cRNA for different connexins. This allowed us to monitor the junctional conductance of the same cell pair in which the dye transfer is being recorded, so that expression levels could be rigorously controlled. An imaging system was then employed to accurately measure the intercellular diffusion of the dye. A two-dimensional model was developed to describe this diffusion, taking into account leak across the membrane, irrevers- 
ible binding to the yolk, and uniform diffusivity through the cytoplasm, all of which are assumed constant for a particular dye, and a variable diffusion across the intercellular interface. This model produced excellent fits to the data, and yielded permeability estimates for the junctional interface. From the known channel conductance for each connexin (see last column in Table 2 for the values employed in this calculation), and the net junctional conductance of that cell pair, we could calculate the number of channels, and hence the permeability of each channel to a particular dye. The initial results of these studies are presented in Table 2.

Of the connexins examined, $\mathrm{Cx} 43$ channels show the highest permeability to all probes, with no significant decrease between the smallest and largest. This would suggest that even the Alexa594 probe (MW 759) is well below the exclusion limit of these channels. Cx32 channels show a slightly reduced permeability to the smallest probe compared to $\mathrm{Cx} 43$ channels, and a marked decrease in permeability to the larger two probes. This decrease is not progressive with the increasing size of the probe, suggesting that there may be some characteristic of the probes distinguished by this channel that changes from the smallest dye (-1 charge) to the larger two dyes $(-2,+1$ charges with a branched ring structure). However, in this case also, it appears that the physical size cut-off of this pore exceeds the range of probes used. Cx26 channels present a different scenario. The permeability to the smallest probe is the same as through $\mathrm{Cx} 32$ channels, but there is a marked and progressive drop in permeability with the larger probes. In fact, it appears that the upper cut-off for Cx26 channels lies between MW 570 and 750 for molecules with these characteristics. These results are consistent with the observations of Harris and colleagues (25) with reconstituted hemichannels where, in mixed populations of $\mathrm{Cx} 32$ and $\mathrm{Cx} 26$, increased Cx26 content resulted in a decrease in the apparent size of the pore. Given the distinct nature of the probes used in the two studies (i.e., neutral vs anionic; carbohydrate based $v s$ conjugated aromatic rings), it seems likely that these conclusions are not specific to the type of molecule, but indeed reflect an absolute size cut-off for the $\mathrm{Cx} 26$ channels that is significantly less than for $\mathrm{Cx} 32$ or $\mathrm{Cx} 43$ channels. It will be of interest in the future to extend these analyses to connexins that show particularly high or low conductances to determine if any correlation with physical dimensions of the channel can be established. These comparisons would also be greatly aided should larger probes in this series be developed.

\section{Selectivity of connexins for natural permeants}

The controlled nature of the studies described in the previous two sections has greatly improved our understanding of the physical basis of selectivity that can be imposed by the connexin composition of gap junction channels. However, it is likely that a balance of several factors, including the obvious properties of charge and size, will determine the net selectivity characteristics

Table 2 - Rates of transfer of a structurally related series of anionic Alexa dyes of increasing size through different connexin channels expressed in Xenopus oocytes.

1Permeability of each channel was calculated from a two-dimensional diffusion model of dye spread between oocytes with known levels of electrical coupling. Channel numbers were estimated from the total intercellular conductance divided by the single channel conductance $\left(\gamma_{\mathrm{j}}\right)$ for each connexin established in the literature (see ${ }^{2}$ and ${ }^{3}$ below).

${ }^{2}$ Single channel conductance for non-phosphorylated Cx43 (dominant form in Xenopus oocytes) (from 13,46).

${ }^{3}$ Single channel conductance for Cx26 and 32 determined in N2A cells (15) and HeLa cells (20).

\begin{tabular}{ccccc}
\hline $\begin{array}{c}\text { Cx } \\
\text { Alexa } 350[\mathrm{MW} 349] \\
(\mathrm{mm} / \mathrm{s})^{1}\end{array}$ & $\begin{array}{c}\text { Alexa 488 }[\mathrm{MW} 570] \\
(\mathrm{mm} / \mathrm{s})^{1}\end{array}$ & $\begin{array}{c}\text { Alexa } 594[\mathrm{MW} 759] \\
(\mathrm{mm} / \mathrm{s})^{1}\end{array}$ & $\begin{array}{c}\gamma_{\mathrm{j}}(\mathrm{pS}) \\
(\text { from lit.) }\end{array}$ \\
\hline 43 & $32 \pm 3(\mathrm{~N}=4)$ & $33 \pm 1(\mathrm{~N}=3)$ & $28 \pm 18(\mathrm{~N}=2)$ & $90^{2}$ \\
32 & $24 \pm 3(\mathrm{~N}=3)$ & 14 & 12 & $55^{3}$ \\
26 & $23 \pm 3(\mathrm{~N}=2)$ & $7 \pm 1(\mathrm{~N}=2)$ & 0.7 & $135^{3}$
\end{tabular}


of these channels. This balance is what will ultimately determine the important permeability characteristics of the channels - those relating to natural metabolites and signaling molecules. The permeability of gap junctions to several of the most important secondary messengers, such as cAMP (27), $\mathrm{Ca}^{2+}$ (28) and $\mathrm{IP}_{3}(28,29)$, as well as metabolites ranging from amino acids to nucleotides, has been documented. However, there has been no comparison between different connexins. Nonetheless, indications that such selectivity may exist are provided from several studies in which it is apparent that transfection of different connexins into a transformed cell line can induce coupling in each case, but only some mediate growth suppression of the tumor line (30-32). Furthermore, the specific connexin that is effective seems to vary with the type of transformed cell. Thus, we felt that it was critical to investigate the degree to which classical measures of cell

Table 3 - Comparative rates of transfer of dye and small metabolites between $\mathrm{C} 6$ glioma cells transfected with different connexins.

${ }^{1}$ Ratio of $\mathrm{C} \times 43$ and $\mathrm{C} \times 32$ transfer taken from the difference in the transfer of the compound between connexin and control transfectants.

${ }^{2} \mathrm{As}$ in 1 , but the ratio of connexin transfer is taken from the difference in the transfer of the compound in the presence of the gap junction blocker $18 \alpha$-carbenoxolone (ACO), and after a 20-min washout.

${ }^{3}$ Transfer is measured as the number of receiver cells filling with dye for each donor cell that is pre-loaded with calcein ester.

4Transfer of metabolites is measured as the percentage of counts for that particular compound (based on HPLC and TLC separations) present in a donor cell that is "captured" in each recipient cell.

\begin{tabular}{lcc}
\hline Compound & \multicolumn{2}{c}{ Ratio of compound transfer - Cx43:Cx32 } \\
\cline { 2 - 3 } & $\begin{array}{c}\text { Cx Transfectant - } \\
\text { control transfectant }\end{array}$ & $\begin{array}{c}\text { ACO washout - } \\
\text { ACO block }\end{array}$ \\
\hline Calcein $^{3}$ & 0.08 & 0.17 \\
Glutathione $^{4}$ & 0.8 & 2.8 \\
Glutamate $^{4}$ & 1.1 & 0.9 \\
ADP4 $^{4}$ & 2.2 & 13.4 \\
ATP $^{4}$ & 3.3 & 10.3
\end{tabular}

coupling reflect the efficiency with which endogenous metabolites are transferred, and ultimately to directly compare the permeability characteristics of different connexins to natural permeants.

Previous studies involving endogenous cellular product transfer through gap junctions had focussed on specific molecules. However, in order to screen broadly for junctional permeants in an unbiased manner, it is necessary to label the metabolite pool in a donor cell population and then capture junctionally transferred material in a recipient population that can then be separated for analysis. To achieve this end, we adopted the preloading strategy analogous to that used for measuring dye coupling (33). A donor population of cells is loaded with a lipidsoluble dye (DiI), and the metabolite pool is labeled with ${ }^{14} \mathrm{C}$ glucose (labeled at all 6 positions). These cells are then mixed with an approximately 6-fold excess of unlabeled receiver cells, and plated at confluence for approximately $2 \mathrm{~h}$, during which time they form gap junctions. Alternatively, they can be plated in the presence of the gap junction blocker, 18 $\alpha$-carbenoxolone (ACO), which can subsequently be washed out to look at capture over a shorter time frame (usually $\sim 15 \mathrm{~min}$ ) that should reflect the rate of transfer of metabolites rather than the steady state levels of distribution that are seen at $2 \mathrm{~h}$. After the coupling period, the cells are harvested and the receiver cells are separated by fluorescent activated cell sorting (FACS). The contents of both donor and receiver cells is then analyzed through several HPLC columns (both size exclusion and ion exchange) and finally by TLC in order to identify specific components that co-migrate with internal standards. To date, we have identified four of the more abundant metabolites (see Table 3) and separated some other components that require further analysis (34).

For these studies we chose a cell line in which the differential effects of connexins had already been demonstrated. Rat C6 
glioma cells are poorly coupled and transformed by most growth criteria. Naus and colleagues had shown that transfection of Cx43 (30), but not Cx32 (31), could normalize the transformed growth of these cells particularly with respect to their saturation density. Hence, we compared control transfectants that showed almost no coupling with Cx43 and Cx32 transfectants (Table 3). Junction-specific transfer of material between cells at steady state (representing the difference between connexin and control transfectants - first column of Table 3 ), and the rate of transfer after ACO washout (second column of Table 3) were compared and expressed as a ratio of the values obtained for the $\mathrm{Cx} 43$ and $\mathrm{Cx} 32$ transfectants.

Using standard dye transfer measures of coupling, the $\mathrm{C} \times 32$ transfectants were coupled between 6 - and 10-fold better than the $\mathrm{Cx} 43$ transfectants. In contrast, however, when the capture of endogenous metabolites is compared, $\mathrm{Cx} 43$ and $\mathrm{Cx} 32$ pass glutamate and glutathione with similar efficiency (ratios of 0.8 and 1.1 at equilibrium, respectively). Nucleotides (specifically ADP and ATP) pass through $\mathrm{Cx} 43$ channels over 10fold faster than through $\mathrm{Cx} 32$ channels, resulting in a 2-3-fold difference in the steady state distribution of these compounds throughout the cell population. Hence, it is apparent that the traditional measure of dye coupling of cells is a poor indicator of the level of intercellular movement of metabolites. Furthermore, this demonstrates for the first time that different connexins can impart significant selectivity to the exchange of information between cells - a difference that is probably to account for the differing phenotypic effects of connexins, even though all induce measurable coupling. Interestingly, an examination of the molecules that show selective transfer through these two gap junctions does not yield any obvious basis for the discrimination. It is probably not based on simply size or charge, but on a discrimination between aspects of the molecule's chem- istry or shape. This is also evident in the results of Harris et al. (25) on reconstituted hemichannels where it appeared that connexin composition affected the relative permeabilities of two compounds as closely related as cAMP and cGMP.

Although there may be some redundancy built into connexin expression patterns in many cells, one would predict from our observations that specialized roles that cannot be subserved by the other connexins are also likely to be present. While many connexin knockouts in mice have not had as dramatic a phenotype as one might have guessed, arguing for redundancy in the system (3537 ), it is also true that there are cases where one connexin has been ablated, and despite the continued presence of another, defects are still observed. A striking example of this is the $\mathrm{Cx} 46$ (38) and 50 knockouts (39), both of which induce cataracts in the eye lens despite the continued functional expression of the other connexin.

\section{The future challenge - defining the molecular basis of selectivity}

Clearly, much needs to be done to fully catalogue the selective permeability characteristics imparted to gap junction channels by their connexin composition. We have only just begun the comparison of different connexins and the cataloguing of natural permeants, and no clear theme has yet emerged. Unlike other channel classes, it is unlikely that the differences in permeability will range over orders of magnitude. They are likely to be subtler, but considering that the permeants will have a limited half-life in the receiver cell, smaller differences could lead to significant differences in biological response. A further complication that will have to be faced is that in many cell systems it is quite likely that heteromeric combinations of connexins form $(25,40-42)$. To date we have only examined the simpler case of homomeric channels. It will be instructive to 
see what properties are dominant when two connexins of differing selectivities are combined. From the reconstituted hemichannel study described above, it already seems that a smaller cut-off limit would tend to be a dominant feature in heteromeric combinations. This may have been an expected result, but properties such as charge selectivity may be harder to predict.

Clearly, our understanding of this process, and the basis of the selectivity patterns seen, will be greatly enhanced with a knowledge of the molecular structure of the pore itself. To date this has been elusive. Original predictions focussed on M3 as the obvious candidate for the pore-lining segment based on its amphipathic character (43). However, some evidence based on cysteine scanning mutagenesis of hemichannels (44), and the effects of mutants associated with CMTX disease (26), have led to the implication of M1 in the lining of the pore. The recent structure of the gap junction at 7A suggests a possible solution to this dilemma in that more than one helix appears to contribute to the pore lining (45). One helix lines the pore along its whole length, while another contributes to the wider cytoplasmic mouth of the pore. Most recently, we have applied the cysteine scanning mutagenesis strategy to whole gap junction channels of $\mathrm{Cx} 32$ using a novel oocyte perfusion assay (developed by F.L. Cao). The results demonstrate that residues along the whole length of M3 are exposed to the aqueous pore, and can react with sulfhydryl reagents that produce partial block of the channel (Skerrett IM, Aronowitz J, Shin J, Kasparek E and Nicholson BJ, unpublished results). Reactivity of a more restricted set of residues is also seen in M1 and M2. However, the introduction of cysteine into $\mathrm{M} 1$ at these reactive sites seems to disrupt channel structure, as indicated by a significant shift in the gating responses of the channels to voltage. These shifts cause the channels to reside predominantly in the closed state in the absence of an applied transjunctional potential, raising the possibility that these reactive sites in M1 are exposed in the closed state of the channel.

As we refine our description of the channel lining, and our understanding of the properties of permeants that are important in establishing the selectivity of gap junction channels, we should be able to piece together a picture of how these intercellular pores establish selective gateways for the exchange of critical information between cells. This represents a challenge for the next decade in the field, and a necessity for truly understanding the role of these channels in regulating multicellular systems.

\section{References}

1. Li H, Liu T-F, Lazrak A, Peracchia C, Goldberg GS, Lampe PD \& J ohnson RG (1996). Properties and regulation of gap junctional hemichannels in the plasma membranes of cultured cells. J ournal of Cell Biology, 134: 1019-1030.

2. Vanoye CG, Vergara LA \& Ruess L (1999). Isolated epithelial cells from amphibian urinary bladder express functional gap junctional hemichannels. American J ournal of Physiology, 276: C279-C284.

3. J ohn SA, Kondo R, Wang SY, Goldhaber J I \& Weiss J N (1999). Connexin-43 hemichannels opened by metabolic inhibition. J ournal of Biological Chemistry,
274: 236-240.

4. Van Eldik LJ , Hertzberg EL, Berdan RC \& Gilula NB (1985). Interaction of calmodulin and other calcium-modulated proteins with mammalian and arthropod junctional membrane proteins. Biochemical and Biophysical Research Communications, 126: 825-832.

5. Yamamoto T, Kardami E \& Nagy J I (1991). Basic fibroblast growth factor in rat brain: localization to glial gap junctions correlates with connexin43 distribution. Brain Research, 554: 336-343.

6. Toyofuku T, Yabuki M, Otsu K, Kuzuya T, Hori M \& Tada M (1998). Direct associa- tion of the gap junction protein connexin43 with ZO-1 in cardiac myocytes. J ournal of Biological Chemistry, 273: 1272512731.

7. Kanemitsu MY, Loo LWM, Simon S, Lau AF \& Eckhart W (1997). Tyrosine phosphorylation of connexin 43 by $\mathrm{v}$-src is mediated by $\mathrm{SH} 2$ and $\mathrm{SH} 3$ domain interactions. J ournal of Biological Chemistry, 272: 22824-22831.

8. Zhou L, Kasperek EM \& Nicholson BJ (1999). Dissection of the molecular basis of pp60 $\mathrm{v}$-src induced gating of connexin43 gap junctions. J ournal of Cell Biology, 114: 1033-1045. 
9. Elfgang $C$, Eckert R, Lichtenberg-Fraté $H$, Butterweck A, Traub O, Klein RA, Hülser DF \& Willecke K (1995). Specific permeability and selective formation of gap junction channels in connexin-transfected HeLa cells. J ournal of Cell Biology, 129: 805-817.

10. Reed KE, Westphale EM, Larson DM, Wang $\mathrm{H}-\mathrm{Z}$, Veenstra RD \& Beyer EC (1993). Molecular cloning and functional expression of human connexin37, an endothelial cell gap junction protein. J ournal of Clinical Investigation, 91: 997-1004.

11. Veenstra RD, Wang HZ, Beblo DA, Chilton MG, Harris AL, Beyer EC \& Brink PR (1995). Selectivity of connexin-specific gap junctions does not correlate with channel conductance. Circulation Research, 77: 1156-1165.

12. Beblo DA \& Veenstra RD (1997). Monovalent cation permeation through the connexin40 gap junction channel: $\mathrm{Cs}, \mathrm{Rb}, \mathrm{K}$, $\mathrm{Na}, \mathrm{Li}, \mathrm{TEA}, \mathrm{TMA}, \mathrm{TBA}$ and effects of anions $\mathrm{Br}, \mathrm{Cl}, \mathrm{F}$, acetate, aspartate, glutamate, and $\mathrm{NO}_{3}$. J ournal of General Physiology, 109: 509-522.

13. Wang H-Z\& Veenstra RD (1997). Monovalent cation and anion selectivity sequences of the rat connexin43 gap junction channel. J ournal of General Physiology, 109: 491-507.

14. Trexler EB, Bennett MVL, Bargiello TA \& Verseilis VK (1996). Voltage gating and permeation in a gap junction hemichannel. Proceedings of the National Academy of Sciences, USA, 93: 5836-5841.

15. Suchyna TM, Chilton M, Nitsche J, Harris AL, Veenstra RD \& Nicholson BJ (1999). Different ionic permeabilities for connexins 26 and 32 produce rectifying gap junction channels. Biophysical J ournal (in press).

16. Cao F, Eckert R, Elfgang $C$, Nitsche JM, Snyder S, Hulser DF, Willecke $K$ \& Nicholson BJ (1998). A quantitative analysis of connexin-specific permeability differences of gap junctions expressed in HeLa transfectants and Xenopus oocytes. J ournal of Cell Science, 111: 31-43.

17. Manthey D, Bukauskas F, Lee CG, Kozak CA \& Willecke K (1999). Molecular cloning and functional expression of the mouse gap junction gene encoding connexin-57 in human HeLa cells. J oumal of Biological Chemistry, 274: 14716-14723.

18. Veenstra RD, Wang HZ, Westphale EM \& Beyer EC (1992). Multiple connexins confer distinct regulatory and conductance properties of gap junctions in developing heart. Circulation Research, 75: 12771283.
19. Veenstra RD, Wang $H Z$, Beyer EC, Ramanan SV \& Brink PR (1994). Connexin37 forms high conductance gap junction channels with subconductance state activity and selective dye and ionic permeabilities. Biophysical J oumal, 66: 19151928.

20. Bukauskas FF, Elfgang C, Willecke $K \&$ Weingart R (1995). Heterotypic gap junction channels (connexin26 - connexin32) violate the paradigm of unitary conductance. Pflügers Archive, European J ournal of Physiology, 429: 870-872.

21. Flagg-Newton J, Simpson I \& Loewenstein WR (1979). Permeability of the cell-to-cell membrane channels in mammalian cell junctions. Science, 205: 404-407.

22. Simpson I, Rose B \& Loewenstein WR (1977). Size limit of molecules permeating the junctional membrane channels. Science, 195: 294-296.

23. Steinberg $\mathrm{TH}$, Civitelli R, Geist ST, Robertson AJ , Hick E, Veenstra RD, Wang H-Z, Warlow PM, Westphale EM, Laing J G \& Beyer EC (1994). Connexin 43 and connexin 45 form gap junctions with different permeabilities in osteoblastic cells. EMBO J oumal, 13: 744-750.

24. Koval M, Geist ST, Westphale EM, Kemendy $A E$, Civitelli $R$, Beyer EC \& Steinberg TH (1995). Transfected connexin45 alters gap junction permeability in cells expressing endogenous connexin43. J ournal of Cell Biology, 130: 987995.

25. Bevans CG, Kordel M, Rhee SK \& Harris AL (1998). Isoform composition of connexin channels determines selectivity among second messengers and uncharged molecules. J ournal of Biological Chemistry, 273: 2808-2816.

26. Oh S, Yi R, Bennett MVL, Brady Trexler E, Verseilis VK \& Bargiello TA (1997). Changes in permeability caused by connexin32 mutations underlie X-linked Charcot-Marie-Tooth disease. Neuron, 19: 927938.

27. Lawrence TS, Beers WH \& Gilula NB (1978). Transmission of hormonal stimulation by cell-to-cell communication. $\mathrm{Na}$ ture, 272: 501-506.

28. Saez J C, Connor J A, Spray DC \& Bennett MV (1989). Hepatocyte gap junctions are permeable to the second messenger, inositol 1,4,5-trisphosphate, and to calcium ions. Proceedings of the National Academy of Sciences, USA, 86: 2708-2712.

29. Sanderson MJ (1995). Intercellular calcium waves mediated by inositol triphosphate. Ciba Foundation Symposium, 188:
175-194.

30. Zhu D, Caveney S, Kidder GM \& Naus CC (1991). Transfection of C6 glioma cells with connexin 43 cDNA: analysis of expression, intercellular coupling, and cell proliferation. Proceedings of the National Academy of Sciences, USA, 88: 18831887.

31. Bond SL, Bechberger J , Khoo NK \& Naus CC (1994). Transfection of C6 glioma cells with connexin32: the effects of expression of a non-endogenous gap junction protein. Cell Growth and Differentiation, 5: 179-186.

32. Mesnil M, Krutovskikh VA, Piccoli C, Elfgang $C$, Traub $\mathrm{O}$, Willecke $\mathrm{K} \&$ Yamasaki H (1995). Negative growth control of HeLa cells by connexin genes: connexin species specificity. Cancer Research, 55: 629-639.

33. Goldberg GS, Bechberger J F \& Naus CC (1995). A pre-loading method of evaluating gap junctional communication by fluorescent dye transfer. Biotechniques, 18: 490-497.

34. Goldberg G, Lampe PD \& Nicholson BJ (1999). Selective transfer of endogenous metabolites through gap junctions composed of different connexins. Nature - Cell Biology (in press).

35. Nelles E, Butzler $C$, J ung D, Temme A, Gabrile H-D, Dahl U, Traub O, Stumpel F, J ungermann K, Zielasek J, Toyka KV, Dermietzel R \& Willecke K (1996). Defective propagation of signals generated by sympathetic nerve stimulation in liver of connexin32 deficient mice. Proceedings of the National Academy of Sciences, USA, 93: 9565-9570.

36. Simon AM, Goodenough DA, Li E \& Paul DL (1997). Female infertility in mice lacking connexin37. Nature, 385: 525-529.

37. Reaume $A C$, deSousa PA, Kulkarni $S$, Langille BL, Zhu D, Davies TC, J ujena SC, Kidder GM \& Rossant J (1995). Cardiac malformations in neonatal mice lacking Cx43. Science, 267: 1831-1834.

38. Gong XH, Li E, Klier G, Kumar N \& Gilula NB (1997). Disruption of alpha(3) connexin gene leads to proteolysis and cataractogenesis in mice. Cell, 91: 833-843.

39. White TW, Goodenough DA \& Paul DL (1998). Targeted ablation of connexin50 in mice results in microphthalmia and zonular pulverulent cataracts. J oumal of Cell Biology, 143: 815-825.

40. J iang J X \& Goodenough DA (1996). Heteromeric connexons in lens gap junction channels. Proceedings of the National Academy of Sciences, USA, 93: 1287-1291.

41. Stauffer KA (1995). The gap junction pro- 
tein $B-1$ connexin (Cx32) and $ß-2$ connexin (Cx26) can form heteromeric hemichannels. J ournal of Biological Chemistry, 270: 6768-6772.

42. He DS \& Burt J M (1998). Function of gap junction channels formed in cells co-expressing connexins 40 and 43. In: Werner RW (Editor), Gap J unctions. IOS Press, Washington, DC, 40-45.

43. Milks LC, Kumar NM, Houghton R, Unwin
$N \&$ Gilula NB (1988). Topology of the 32-kD liver gap junction protein determined by site-directed antibody localizations. EMBO J oumal, 7: 2967-2975.

44. Pfahnl A, Zhou X-W, Tian J, Wemer R \& Dahl $G$ (1996). Mapping of the pore of gap junction channels by cysteine-scanning mutagenesis. Biophysical J ournal, 70: 31 (Abstract).

45. Unger VM, Kumar NM, Gilula NB \&
Yeager M (1999). Three-dimensional structure of a recombinant gap junction membrane channel. Science, 283: 17761780.

46. Moreno AP, Fishman GI \& Spray DC (1992). Phosphorylation shifts unitary conductance and modifies voltage dependent kinetics of human connexin43 gap junction channels. Biophysical J ournal, 61: 51-53. 